\title{
Saúde e exercício físico como instrumento terapêutico: Que papel para as revistas científicas?
}

\author{
Physical exercise as a therapeutic tool: What role for scientific journals?
}

\section{J. Vasconcelos-Raposo}

Director da Revista Motricidade - Universidade de Trás-os-Montes e Alto Douro

Neste ensaio apresentamos dois temas que pretendemos interligar. O primeiro, prende-se, sobretudo, com a promoção do Exercício Físico (EF) enquanto ferramenta terapêutica que tem sido negligenciada pelo sistema de saúde. Apresentamos, também, razões para que se possa potenciar os argumentos a favor da inclusão dos profissionais da Saúde e Exercício nas equipas terapêuticas. No segundo tema, abordaremos, de forma crítica, o papel que as revistas científicas poderiam assumir na consolidação da criação dos novos nichos de actividade profissional, no âmbito da saúde.

Com este ensaio, e com algumas das afirmações nele apresentadas, procuramos ser provocadores e assim abrir espaço para o diálogo, pois sabemos que o correcto estará algures entre o que aqui se afirma e o que outros dirão, com o intuito de sermos todos mais eficientes na redefinição de práticas de investigação e de divulgação do saber desenvolvido de forma mais eficaz.

A relação entre Exercício e Saúde, tanto física como mental, é algo que vai para quase 20 anos que tem sido alvo persistente de investigação e objecto de recomendação por parte das mais prestigiadas autoridades científicas e, no caso dos USA, pelo próprio Surgeon General. Na literatura da especialidade defende-se que a actividade física é uma forma eficaz para contribuir para a redução das mortes evitáveis. Entenda-se como mortes evitáveis aquelas que teoricamente têm lugar mais cedo no ciclo da vida das pessoas por não adesão a comportamentos que contrariam os agentes patológicos que conduzem a uma morte "antecipada".
Para os sistemas de saúde, o conceito de "mortes evitáveis" conceito que reúna consenso, na medida em que tem sido apresentado como um indicador claro das fragilidades dos serviços de cuidados médicos, ainda que a realidade não seja essa. As fragilidades são do sistema, mais concretamente são dos agentes responsáveis que podem ser identificados ao nível das definições de políticas de saúde, enquanto os médicos são executores dessas medidas. Por esta razão, importa sermos claros sobre esta matéria e até mais rigorosos na contextualização do uso deste conceito. Assim, quando falamos de serviços de cuidados médicos referimo-nos às propostas e políticas de saúde que são impostas pelo "poder político instalado" às várias classes profissionais que intervêm na promoção da saúde e no tratamento de patologias. Em momento algum do nosso argumento teremos em consideração a relação médico doente, apesar das problemáticas por nós abordadas terem repercussões nessa relação, na medida em que, perante o que lhes é disponibilizado, os prestadores de serviços ficam mais ou menos habilitados a actuar de acordo com o que pensam ser os métodos e as técnicas mais eficazes para os exames e consequente terapêutica.

O poder político instalado tem por necessidade de agir com um sentido de obrigação para sobreviver no poder, e por essa razão, os governos alternam-se e a fraca qualidade de serviços existente tende a permanecer, assim como as reivindicações dos prestadores de serviços por melhores 
condições técnico-profissionais para o exercício das suas actividades. Todas as práticas políticas são feitas em nome dos cidadãos, mas quando estudamos a qualidade de vida das populações rapidamente constatamos que as políticas de saúde pouco ou nada cuidam deles. As políticas de saúde ficam à mercê desta lógica político-partidária.

Se para os sistemas de saúde o conceito de mortes evitáveis não é consensual, já para os profissionais dos serviços curativos, assim como para os que intervêm mais directamente na prevenção, ele é, em geral, da maior relevância. Para os Psicólogos da Saúde e do Exercício, este é um conceito pilar para a justificação dos múltiplos campos da sua acção, uma vez que estes enquanto profissionais são os verdadeiros especialistas no que se refere a mudanças comportamentais, tanto a nível individual como colectivo. Lamentavelmente, este facto tende a ser negligenciado quer na formação dos psicólogos como das instituições que regra geral intervêm no âmbito da saúde.

De uma forma generalizada poderemos dizer que o que está em causa é a identificação dos comportamentos de risco e as intervenções ao nível da Promoção/ Educação para a Saúde. As intervenções de carácter preventivo tendem a privilegiar, entre outros, os seguintes comportamentos de risco: hábitos tabágicos, dietas ricas em gordura, inactividade física, obesidade, diabetes, consumo de álcool, entre outros. No seu conjunto estes tendem a ser responsáveis por mais de $80 \%$ dos acidentes cardiovasculares e estão, também, associados a outras patologias, entre as quais destacamos alguns tipos de cancro. Estes valores tendem a ser superiores na população com doença mental.

Estes comportamentos são, tradicionalmente, os factores de risco sobre os quais tendem a recair as acções de promoção e educação para a saúde. No entanto, em termos históricos, as estratégias de prevenção focadas em intervenções de carácter monodisciplinar, como a educação alimentar, a adesão a prática de actividade física e perda de peso, têm-se demonstrado pouco eficazes e particularmente dispendiosas. Os problemas persistem, tal como sempre existiram e, em determinados casos, os dados epidemiológicos sugerem agravamento, independentemente do investimento que tem sido feito tanto ao nível da pesquisa como das acções para a promoção da saúde.

Importa olhar às eventuais causas para a persistência e, por vezes, agravamento ao nível da incidência das designadas doenças hipocinéticas. Sabemos que não se podem fazer campanhas de promoção da saúde sem que estas estejam devidamente consolidadas em fortes evidências empíricas. Por esta razão, em nossa opinião, importa analisar a forma como os pesquisadores têm contribuído para a solução do problema. Para isso, julgamos necessário reflectir sobre a qualidade da ciência que encontramos publicada. Mas vamo-nos centrar no que acontece no mundo de língua portuguesa, porque é aquele que prioritariamente nos preocupa.

Quanto à prática científica, o que nos é dado a observar tanto ao nível do que é publicado como do que verificamos como membros de júris de concursos para a progressão na carreira académica, ao nível do ensino superior, é que os aspectos qualitativos dos curriculum vitae (CV), cada vez mais, tendem a ser relegados para um plano secundário face ao número de publicações. Assim, a academia, com todos os seus indicadores bibliométricos, acaba por encorajar uma prática que tem por objectivo o acrescentar de linhas ao $\mathrm{CV}$, independentemente da qualidade científica que elas possam representar. Aos docentes investigadores foi exigido que se adaptassem a este jogo numérico e que desenvolvessem práticas e estratégias que possibilitassem dar resposta às novas exigências. Com o decorrer do tempo, estas práticas foram sendo legitimadas e consolidadas consoante encontravam espaço para publicação nas revistas científicas que neste processo acabaram assumindo o papel de agentes legitimadores e reprodutores dessa 
forma de estar na ciência. Mas há nobres excepções no espaço Lusófono, e não só, tanto ao nível pessoal como das revistas científicas.

Quanto aos desenhos da pesquisa que pretende estudar a relação entre a prática de exercício físico e a saúde, constatámos que é escasso o número de estudos que apresentam de forma detalhada os programas de $E F$, descrevendo os volumes e as intensidades, assim como os efeitos respeitantes a cada um dos níveis destas, enquanto variáveis independentes. Este aspecto é agravado quando tomamos em consideração o tamanho das amostras e a escassa informação proporcionada no que se refere aos critérios de inclusão e exclusão dos sujeitos estudados. $\mathrm{Na}$ sua maioria os trabalhos tendem a recorrer às amostragens por conveniência. Amostras mal caracterizadas associadas à falta de critérios de selecção acabam por ter um efeito minimizador quanto à relevância dos resultados produzidos e a consequente utilidade para os profissionais que integram o sistema de cuidados médicos.

As disciplinas científicas que reclamam um lugar nos domínios da saúde são várias e tudo indica que continuarão a crescer. No nosso ensaio debruçamo-nos sobre os contributos que os profissionais treinados especificamente em exercício e saúde podem dar e quais os caminhos a trilhar.

Os investigadores na área do Exercício e Saúde têm feito progressos científicos verdadeiramente expressivos. Souberam ultrapassar com sucesso as fronteiras disciplinares e, de igual modo, estabeleceram inequivocamente a importância da actividade física como forma eficaz para prevenir doenças e lançaram o debate sobre a utilização do exercício físico como instrumento terapêutico. Mas, apesar disto, continuamos a constatar a ausência da inclusão destes profissionais nas equipas terapêuticas.

Como sempre as respostas podem encontrar-se em múltiplas formulas e perspectivas. Poderíamos recorrer ao argumento de natureza política ou ao do cooperativismo da classe médica ou, eventualmente, outros. Julgamos que esses são argumentos já cansados e que na realidade importa explorar novas fronteiras para os profissionais do Exercício Físico e Saúde comunicarem eficazmente com os restantes agentes que intervêm nos cuidados médicos sem se escusarem com falsas desculpas.

Até hoje, com base na nossa experiência profissional e pessoal, só encontrámos profissionais, ao nível dos cuidados médicos, que se apresentam curiosos e desejosos de aprender algo mais sobre o porquê e o como é que efectivamente $\mathrm{O}$ EF tem o efeito terapêutico que a investigação científica sugere. As respostas a encontrar deverão ser dadas tendo em consideração o "ETHOS" das classes profissionais envolvidas. Por exemplo, para fazer entender aos médicos como o EF pode ser um instrumento terapêutico relevante, não basta dizê-lo e apresentar resultados de investigação que são de carácter generalista. Importa encontrar um discurso e linguagem que faça com que as evidências empíricas sejam entendidas à luz das lentes interpretativas que os diferentes profissionais utilizam, fruto da sua formação científica.

Importa não esquecer que há um recente $\mathrm{e}$ crescente interesse dos médicos, e outros profissionais, pela importância do EF como agente terapêutico. O seu envolvimento, ao nível da pesquisa representa novos desafios para os profissionais da EF. Agora mais do que nunca a pesquisa deverá tomar uma nova roupagem e redefinir as prioridades quanto a unidades de análise. Estudos sobre a dosagem do exercício físico e os seus efeitos são aqueles que faltam e são urgentes para a formação dos prestadores de cuidados médicos. Para os investigadores que pretendem promover $\mathrm{o}$ Exercício como terapêutica, importa entender que os seus argumentos terão de ser feitos nos mesmos moldes a que a indústria farmacêutica recorre para fazer prevalecer as vantagens dos medicamentos a propor.

Quando tomamos, entre outros, também estes aspectos, parece-nos evidente que é urgente repensar a formação académica e 
científica da nova geração de docentes e pesquisadores em geral, mas de uma forma particular no que se refere à área científica da Saúde e Exercício. É urgente modernizar os conhecimentos e os métodos pedagógicos ultrapassando as práticas vigentes e encontrando novos formatos de intervenção na formação de pesquisadores.

Actualmente, as instituições de ensino superior estão, ainda, prisioneiras de métodos que se alicerçam no recrutamento daqueles que os professores definem como os melhores para os integrar nas suas equipas de pesquisa. Dizer que é necessário promover a autonomia dos formandos seria esquecer, os últimos 20 anos de carreira como docente, e investigador, e das múltiplas oportunidades proporcionadas a alunos, guiando-os por novos caminhos na prática científica. Num olhar retrospectivo constata-se que após um vasto investimento, tanto em tempo como em recursos financeiros, tanto institucionais como pessoais, constatamos que a opção desses formados tem sido a de aderirem ao caminho mais fácil: $\mathrm{O}$ da produção de trabalhos que acabam mais cedo ou mais tarde por cair na mecanização da prática investigativa. Isto é, encontram uma área do conhecimento em que se dizem "especializar" e dedicam-se à recolha, tratamento e escrita de trabalhos que posteriormente são publicados. Mas em última análise, os contributos para o aprofundamento teórico ficam aquém do que se pretende com a investigação científica. A perspectiva reprodutiva do saber perde-se nestas dinâmicas.

Por último, falemos da relevância das revistas científicas neste processo que, apesar de complexo, nos parece ser de análise relativamente fácil.

As revistas científicas não podem deixar de assumir uma quota-parte da fragilização que se tem vindo a verificar ao nível da produção científica. Sem querermos ser exaustivos focaremos cinco aspectos que se nos apresentam como os mais vulneráveis à aplicação de novas políticas editoriais. Em primeiro lugar, descuraram os aspectos qualitativos da investigação e ficaram menos exigentes ao nível da teorização. Em segundo lugar, adoptaram procedimentos em torno dos quais se refugiam para diluir as suas responsabilidades, delegando para os "peer reviewers" a grande fatia da responsabilidade de aceitação para publicarem os trabalhos. Em terceiro lugar, retiraram-se da discussão relativamente ao papel que desempenham no desenvolvimento da ciência e tecnologia e, consequentemente, das sociedades em geral. Em quarto lugar, assistem passivamente à aplicação de políticas de desenvolvimento científico que mais se parecem com a promoção de políticas de promoção de colonização intelectual. Referimo-nos a não tomarem posição colectiva quanto ao facto de negligenciarem as revistas de língua portuguesa privilegiando as de língua inglesa, apesar dos governos dos seus países, através das suas agências para o desenvolvimento da ciência investirem montantes razoáveis no financiamento das revistas científicas de língua portuguesa. Esta prática parece esquecer aqueles que são, efectivamente, os níveis linguísticos dos estudantes e da comunidade científica Lusófona. Tendo a linguagem como elemento de referência, pensamos ser necessário priorizar o aumento significativo do número de pesquisadores, para depois se proceder à eventual aplicação de critérios mais selectivos. Em quinto lugar, as revistas deverão ter um papel activo junto das instituições de ensino superior fazendo-as repensar o papel discriminativo que têm perante a qualidade da pesquisa publicada nas revistas de língua portuguesa.

Por último, não poderemos deixar de ser realistas e relembrar que todas estas mudanças passam, forçosamente, por uma mudança de cultura científica, onde a qualidade volte a ser o centro do reconhecimento académico e não tanto a soma de publicações que, infelizmente, numa percentagem elevada, tendem a resultar de trabalho introdutórios realizados por académicos de nível de graduação e de pós- 
graduação, e nem sempre escritos e submetidos sob a supervisão dos docentes investigadores, como seria desejável.

Procurando sintetizar o que foi até aqui dito destacaríamos os seguintes aspectos como sendo aqueles em que as revistas científicas podem e devem ter um papel activo:

1. É urgente contribuir para a concretização do princípio humanista de que a saúde é um bem colectivo e individual. Isto implica contrariar as práticas que a transformam num instrumento políticoideológico.

2. Enquanto membros activos e centrais de uma comunidade científica que é cada vez mais de natureza universalista, procurar contribuir para o incremento de melhores serviços terapêuticos. Isto poderá ser feito através da publicação dos estudos que proporcionam as evidências para a adesão a novas práticas, assim como abrindo espaço para o debate sobre as necessárias redefinições de prioridades que coloquem o cidadão em primeiro lugar.

3. Redefinir as políticas editoriais de forma a promover a publicação de estudos que evidenciem as vantagens económicas que advêm do investimento na promoção da saúde através do EF.

4. As revistas deverão ter um papel mais interventivo no desenvolvimento e promoção de uma linguagem científica que facilite $o$ diálogo e a investigação multidisciplinar.

5. Os editores, através das suas políticas editoriais deverão promover a inovação metodológica e teórica incentivando a publicação de trabalhos que visem redefinir as fronteiras científicas.

Em suma, em linhas gerais, neste trabalho, detalhamos aqueles que são os princípios orientadores para a implementação das políticas editoriais da Motricidade para os próximos anos, e para a área da saúde, de uma forma muito particular.

(c) EY-No Todo o conteúdo da revista Motricidade está licenciado sob a Creative Commons, excepto quando especificado em contrário e nos conteúdos retirados de outras fontes bibliográficas. 